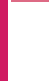

\section{WOMEN IN CANCER THEMATIC REVIEW \\ Thyroid-stimulating hormone in thyroid cancer: does it matter?}

\author{
Hannah Nieto1,2 and Kristien Boelaert',2 \\ 1'Institute of Metabolism and Systems Research, University of Birmingham, Edgbaston, Birmingham, UK \\ ${ }^{2}$ Centre for Endocrinology, Diabetes and Metabolism, Birmingham Health Partners, Birmingham, UK
}

\author{
Correspondence \\ should be addressed \\ to K Boelaert \\ Email \\ k.boelaert@bham.ac.uk
}

\begin{abstract}
Differentiated thyroid cancer is the most common endocrine malignancy and the incidence is increasing rapidly worldwide. Appropriate diagnosis and post-treatment monitoring of patients with thyroid tumours are critical. Fine needle aspiration cytology remains the gold standard for diagnosing thyroid cancer, and although there have been significant refinements to this technique, diagnostic surgery is often required for patients suspected to have malignancy. Serum thyroid-stimulating hormone (TSH) is higher in patients with malignant thyroid nodules than in those with benign disease, and TSH is proportionally increased in more aggressive tumours. Importantly, we have shown that the pre-operative serum TSH concentration independently predicts the presence of malignancy in subjects presenting with thyroid nodules. Establishing the use of TSH measurements in algorithms identifying high-risk thyroid nodules in routine clinical practice represents an exciting, cost-efficient and non-invasive approach to optimise thyroid cancer diagnosis. Binding of TSH to receptors on thyrocytes stimulates a number of growth promoting pathways both in normal and malignant thyroid cells, and TSH suppression with high doses of levothyroxine is routinely used after thyroidectomy to prevent cancer recurrence, especially in high-risk tumours. This review examines the relationship between serum TSH and thyroid cancer and reflects on the clinical potential of TSH measurements in diagnosis and disease monitoring.
\end{abstract}

\section{Introduction}

Differentiated thyroid malignancy is the most common endocrine malignancy and over the last few decades, its incidence has increased dramatically worldwide (Sipos \& Mazzaferri 2010, Kitahara \& Sosa 2016). It is currently the fifth most common malignancy in women in the US and an estimated 62,000 new cases were found in North American men and women in 2015 (American Cancer Society 2015). Thyroid cancer causes more deaths than any other endocrine cancer (Monson 2000), and there will be an estimated 1980 deaths from thyroid cancer in the US in 2016 (American Cancer Society 2016).
The reasons for the observed increase in incidence have been widely debated (Wartofsky 2010) and include enhanced detection of subclinical thyroid cancer due to the growing use of diagnostic imaging and exposure to a number of environmental factors (Kitahara \& Sosa 2016). Although better access to health care in countries with high socioeconomic status may in part explain the rising incidence, observations of increased thyroid cancer rates in lower socioeconomic countries, an increasing number of larger tumours and the changing thyroid cancer molecular profiles indicate that other

This paper is part of a special section celebrating Women Working Within the Field of Cancer. The Guest Editors for this section were Charis Eng and

Deborah Marsh. Downloaded from Bioscientifica.com at 04/26/2023 12:13:28AM 
factors are likely to be involved (Vigneri et al. 2015). A number of disease-modifiable factors including obesity have been identified as potential aetiological factors (Schmid et al. 2015). Moreover, a variety of thyroidspecific environmental carcinogens have been implicated including ionising radiation, increased dietary iodine intake and environmental pollutants (Vigneri et al. 2015). Overall, the observed changes in thyroid cancer incidence are likely due to a combination of detection bias and true increases in incidence.

Thyroid cancer often presents as a solitary nodule or as a part of a multinodular goitre. This creates an important clinical dilemma as thyroid nodules are very common in $50-67 \%$ of the population, and more than $90 \%$ are benign (Mazzaferri 1992, Hegedus 2004, Popoveniuc \& Jonklaas 2012, Durante et al. 2015). Detection rates of thyroid nodules are increasing due to widespread use of imaging modalities in advanced health care systems (Cramer et al. 2010, Popoveniuc \& Jonklaas 2012). Although incidental thyroid neoplasms have long been recognised due to their presence during post-mortem examinations (Dean \& Gharib 2008), there is a significant and increasing clinical burden associated with detecting this disease in patients (Brito et al. 2014), for whom the differentiation between aggressive and indolent diagnoses is crucial (Cabanillas et al. 2016a).

There are a number of well-established and evolving clinical tools to discern malignant from benign thyroid nodules (He et al. 2016). Most international guidelines recommend the use of a combination of diagnostic tools, including measurement of thyroid-stimulating hormone (TSH) to assess functional thyroid status, high resolution ultrasonography (US) scanning to assess the morphological characteristics of the thyroid and nodule(s) and fine needle aspiration for cytological evaluation of the presence of malignancy (Hegedus et al. 2003, Perros et al. 2014, Pitoia \& Miyauchi 2015). In recent years, the use of panels of molecular markers to refine the cytological diagnosis of malignancy has received significant attention, although these tests are very expensive and not used routinely in all centres (Xing et al. 2013). As most benign nodules do not require further intervention, it is pertinent that thyroid malignancy is diagnosed accurately and further refinement of current diagnostic approaches is required.

If malignancy is diagnosed, surgery is the primary treatment modality for differentiated thyroid cancer, followed by adjuvant radioiodine ablative therapy in a significant number of patients (Burns \& Zeiger 2010, Perros et al. 2014, Pitoia \& Miyauchi 2015). As TSH is a growth factor for thyroid cells, therapy with suppressive doses of levothyroxine is often used postoperatively, and this has long been known to positively affect outcomes in differentiated thyroid cancer (Mazzaferri \& Jhiang 1994, Pujol et al. 1996, McLeod et al. 2012). Current guidelines recommend the medium-to-long-term use of TSH suppression in high-risk thyroid cancer but not in lower-risk tumours because of the health risks associated with the induction of subclinical and overt thyrotoxicosis (Perros et al. 2014, Pitoia \& Miyauchi 2015).

The diagnosis and post-therapy monitoring of patients with thyroid nodules and cancer is important. We were the first to publish that serum TSH is raised in patients with malignant thyroid nodules compared with those with benign disease (Boelaert et al. 2006), and subsequent studies have shown that pre-operative serum TSH is proportionally higher in those with more aggressive disease (Boelaert et al. 2006, Jonklaas et al. 2008, Haymart et al. 2009, McLeod et al. 2014, Fighera et al. 2015). This review aims to explore the relationship between TSH and thyroid cancer, both before and after a diagnosis of malignancy is made.

\section{Thyroid-stimulating hormone}

\section{Hormone structure and biochemical details}

Thyroid-stimulating hormone (TSH) is a two-subunit glycoprotein, released from the pituitary gland in response to hypothalamic release of thyrotropin-releasing hormone (TRH). The alpha subunit of the glycoprotein is similar to that of luteinising hormone (LH) and follicle-stimulating hormone (FSH), with specificity only related to the beta subunit. TSH, or thyrotropin, stimulates the thyroid to produce and secrete thyroxine (T4) and triiodothyronine (T3). The released T4 becomes effective once converted peripherally to triiodothyronine (T3) by deiodinase enzymes. The functionally active circulating hormones provide a feedback loop directly to both the hypothalamus and the pituitary suppressing further release of TSH and TRH, thereby maintaining homeostatic control of the hypothalamic-pituitary-thyroid axis (Magner 1989, Szkudlinski et al. 2002, Sarapura et al. 2011).

\section{TSH function in the normal thyroid}

TSH acts on thyroid cell signalling through the TSH receptor, which is found predominantly on follicular thyroid cells. TSH is a growth factor for thyrocytes, with prolonged exposure causing hyperplasia and hypertrophy

Published by Bioscientifica Ltd. 
(Sarapura et al. 2011). Stimulation of the TSH receptor causes activation of the adenylate cyclase pathway, resulting in alterations in cell-cycle proteins causing changes in thyroid gland growth and cell morphology, as well as the production of thyroid hormones. The effects of TSH can be broadly summarised as follows: synthesis of thyroid hormones, thyroid gland growth, changes in thyrocyte morphology, regulation of post-transcriptional activation of the sodium iodide symporter (NIS) and modulating extra-thyroidal effects (Sarapura et al. 2011).

\section{Diagnosing thyroid malignancy}

\section{Types of thyroid cancer}

Thyroid cancers arise from thyroid follicular cells or parafollicular cells. Differentiated thyroid cancer (DTC) includes two subtypes, papillary and follicular cancers, both of which arise from follicular cells and together make up $90 \%$ of thyroid cancers. Papillary thyroid cancers are the most common and represent $85 \%$ of all thyroid malignancies. Medullary thyroid cancers account for $3-4 \%$ of all thyroid cancers and $80 \%$ arise from sporadic mutations, whereas the remainder are hereditary, usually as part of multiple endocrine neoplasia syndromes. Finally, thyroid cancers can be undifferentiated, referred to as anaplastic thyroid cancers, and these tumours have the most aggressive phenotype and the worst prognosis with median survival rates of 3-7 months (Cabanillas et al. 2016b).

\section{Current diagnostic approaches and limitations}

Guidelines recommend that patients suspected to have thyroid malignancy are assessed by a physician with a specialist interest in thyroid cancer care, and who is a regular member of the multi-disciplinary team (Perros et al. 2014). It is paramount to perform a full clinical assessment, which includes taking a personal and family history as well as careful clinical examination (Hegedus et al. 2003, Hegedus 2004, Perros et al. 2014, Pitoia \& Miyauchi 2015). In many cases, however, thyroid glands harbouring malignancy are clinically indistinguishable from those that do not, and there is substantial variation among practitioners in evaluating nodules. Features suggestive of malignancy include the presence of firm, fixed thyroid lumps, vocal cord palsy, a positive family history, rapid nodule growth and being at the extremities of age ( $>60$ years or $<20$ years) (Hegedus et al. 2003). Table 1 displays clinical characteristics associated with an increased risk of malignancy.
Table 1 Clinical features suggestive of thyroid malignancy (Hegedus 2004, Popoveniuc \& Jonklaas 2012).

\section{History}

Family Hx of MEN, MTC, PTC

History of head and neck irradiation as child or adolescent non-Hodgkin lymphoma and irradiation

Age $<20$

Age $>70$

Male gender

Symptoms of compression: hoarseness, dysphagia, dyspnoea, cough, dysphonia
History of Hodgkin and

\section{Physical examination}

Firm nodule

Nodule fixed to adjacent structures

Growth of nodules, especially during therapy to suppress TSH

Abnormal cervical lymph nodes

Vocal cord paralysis
The serum TSH concentration is routinely measured to exclude the presence of a toxic nodular disease causing subclinical or overt hyperthyroidism in all patients (Hegedus et al. 2003, Perros et al. 2014, Pitoia \& Miyauchi 2015). If the TSH is below the laboratory reference range, assays for free triiodothyronine (fT3) and free thyroxine (fT4) are required to exclude overt hyperthyroidism (raised free T4 and free T3) or 'T3-toxicosis' (raised serum-free T3 alone). Similarly, if TSH is raised, then overt hypothyroidism must be excluded (this being indicated by low fT4 with a raised TSH concentration). Although virtually all patients with thyroid carcinoma are euthyroid, the presence of a suppressed serum thyrotropin (TSH) level (generally indicative of subclinical or overt thyrotoxicosis) does not rule out the presence of malignancy (Hegedus et al. 2003, Hegedus 2004, Perros et al. 2014, Pitoia \& Miyauchi 2015). Measurement of serum thyroglobulin is of little value in the initial diagnosis of thyroid cancer, whereas this remains an important tumour marker in the follow-up of patients with thyroid cancer (Perros et al. 2014, Pitoia \& Miyauchi 2015). Measurements of basal plasma calcitonin and carcino-embryonic antigen (CEA) are useful if medullary carcinoma is suspected but do not form part of the routine evaluation of thyroid nodules (Perros et al. 2014).

Thyroid ultrasonography is an extremely sensitive tool for the diagnosis of thyroid nodules and may be specific in diagnosing papillary thyroid cancer (Cesur et al. 2006, Hambly et al. 2011). Moreover, this imaging modality aids the decision-making processes of which nodules to target for fine needle aspiration biopsy (FNAB) and increases the diagnostic yield of thyroid cell sampling (Perros et al. 2014, American Cancer Society 2015, Pitoia \& Miyauchi 2015). Multiple studies have confirmed typical sonographic features associated with increased risks of

Published by Bioscientifica Ltd. 
malignancy (Table 2) (Frates et al. 2005, Hambly et al. 2011, Lee et al. 2011), and current guidelines now recommend the use of a combination of these features in algorithms predicting the likelihood of thyroid malignancy as well as the selection of nodules requiring FNAB (Perros et al. 2014, Haugen et al. 2015, Pitoia \& Miyauchi 2015). Highresolution ultrasonography by an experienced operator is highly recommended in the initial evaluation of patients with thyroid nodules.

Fine needle aspiration cytology remains the gold standard to confirm the absence or presence of thyroid malignancy. The results can confirm that a nodule is benign, triage patients requiring diagnostic surgery or confirm a diagnosis of malignancy enabling one-step therapeutic surgery (Perros et al. 2014, Pitoia \& Miyauchi 2015). In the UK, cytology results are reported using the THY classification (The Royal College of Pathologists 2009), whereas in the US, the Bethesda scoring system (Bongiovanni et al. 2012) is used. Despite accuracy of diagnosis in the majority of thyroid nodules, FNAC has drawbacks including the sometimes high rate of insufficient/inadequate samples, the inability to distinguish between benign and malignant follicular lesions and difficulties in detecting follicular variant papillary carcinomas (Sangalli et al. 2006, Rago et al. 2007).

Indeterminate or suspicious thyroid lesions represent $10-26 \%$ of nodules evaluated cytologically. These nodules usually require diagnostic surgery, and a median 34\% of patients with indeterminate nodules have thyroid malignancy (Xing et al. 2013). To avoid unnecessary thyroidectomy, a number of centres use gene expression classifiers or mutation analysis panels to further refine the cytological diagnosis. These diagnostic tools, however, are very expensive and only routinely available in a limited number of centres worldwide (Bernet et al. 2014, Pitoia $\&$ Miyauchi 2015). Although there have been significant advances in our current diagnostic approaches for thyroid cancer, further cost-efficient and easily applicable approaches are needed to allow informed decision making for both physicians and patients when evaluating the likelihood of malignancy in thyroid nodules.

\section{Serum TSH in the diagnosis of thyroid cancer}

\section{TSH and promotion of thyroid cancer growth}

Several studies including two large meta-analyses (McLeod et al. 2012, Zheng et al. 2016) have confirmed that higher serum TSH is associated with an increased risk of differentiated thyroid cancer. Table 3 demonstrates a range of original research studies investigating the link between serum TSH concentrations and differentiated thyroid cancer. Importantly, several studies have shown higher TSH to predict thyroid malignancy, independent of other risk factors including patients' age and gender and a positive family history (McLeod et al. 2012, Kim et al. 2013). The first study was performed by our group, and demonstrated an increase in risk of diagnosis of malignancy in parallel with an increase in serum TSH (Boelaert et al. 2006). The lowest risk of thyroid cancer diagnosis was in those with a TSH below the lower limit of the reference range $(<0.4 \mathrm{IU} / \mathrm{L})$. There was a significant cut-off at serum TSH of $0.9 \mathrm{IU} / \mathrm{L}$, with an increased risk of cancer diagnosis in those with serum TSH concentrations above this. The highest risk of cancer diagnosis was in the group with subclinical hypothyroidism who had serum TSH $>5.5 \mathrm{IU} / \mathrm{L}$. Importantly we found that, even within the normal range, higher TSH concentrations correlate with a higher risk of DTC, and this was subsequently confirmed by others (Haymart et al. 2008).

Higher pre-operative serum TSH concentrations have also been associated with more advanced cancer stage at diagnosis. Mean serum TSH levels were higher in those with stage III and IV disease and in those with larger tumours or in cancers associated with lymph node metastases (Haymart et al. 2008, Fiore et al. 2009, Shi et al. 2016). A meta-analysis of 28 studies, analysing 42,032 control subjects and 5786 patients with thyroid cancers has confirmed that higher pre-operative TSH levels are associated with increased risk of thyroid malignancy as well as a correlation with higher disease grade (McLeod et al. 2012). A more recent metaanalysis of 56 studies encompassing 20,227 thyroid cancer cases and 50,003 controls with benign thyroid

Table 2 US features associated with thyroid malignancy (Perros et al. 2014)

\section{Benign nodule}

Spongiform/honeycomb

Purely cystic

Egg shell calcification

Isoechoic/hyperechoic (hypoechoic halo)

Peripheral vascularity

\section{Malignant nodule: papillary/medullary}

Solid and hypoechoic Irregular margin Intranodular vascularity

Absence of halo

Taller than wide

Microcalcifications

\section{Follicular lesion}

Hyperechoic/homogeneous/halo benign Hypoechogenicity/loss of halo suspicious 
Table 3 Summary of studies investigating serum TSH and thyroid cancer diagnosis.

\begin{tabular}{|c|c|c|c|c|c|}
\hline Reference & Journal & $\begin{array}{c}\text { Number of } \\
\text { patients }\end{array}$ & $\begin{array}{l}\text { Country of } \\
\text { study }\end{array}$ & Significant findings & $\begin{array}{l}\text { Serum TSH } \\
\text { 'cut-off' value* }\end{array}$ \\
\hline Boelaert et al. (2006) & $\begin{array}{l}\text { Journal of Clinical } \\
\text { Endocrinology and } \\
\text { Metabolism }\end{array}$ & 1500 & UK & $\begin{array}{l}\text { Serum TSH is an independent } \\
\text { predictor of malignancy in } \\
\text { thyroid nodules. Risk of } \\
\text { thyroid cancer rises in parallel } \\
\text { with serum TSH in the normal } \\
\text { range. }\end{array}$ & $0.9 \mathrm{mlU} / \mathrm{L}$ \\
\hline Polyzos et al. (2008) & $\begin{array}{l}\text { Journal of Cancer } \\
\text { Research and } \\
\text { Clinical Oncology }\end{array}$ & 565 & Greece & $\begin{array}{l}\text { Higher rates of thyroid } \\
\text { malignancy in patients with } \\
\text { TSH in upper tertile of } \\
\text { normal range. }\end{array}$ & $1.5 \mathrm{mlU} / \mathrm{L}$ \\
\hline Haymart et al. (2008) & $\begin{array}{l}\text { Journal of Clinical } \\
\text { Endocrinology and } \\
\text { Metabolism }\end{array}$ & 843 & USA & $\begin{array}{l}\text { Higher serum TSH is } \\
\text { associated with advanced } \\
\text { stage-differentiated thyroid } \\
\text { cancer. }\end{array}$ & $1.4 \mathrm{mlU} / \mathrm{L}$ \\
\hline Jonklaas et al. (2008) & Thyroid & 50 & USA & $\begin{array}{l}\text { Higher TSH is associated with } \\
\text { increased likelihood of } \\
\text { diagnosis of thyroid cancer. } \\
\text { Patients with thyroid cancer } \\
\text { have lower serum total T3 } \\
\text { concentrations. }\end{array}$ & $1.8 \mathrm{mlU} / \mathrm{L}$ \\
\hline Haymart et al. (2009) & Clinical Endocrinology & 1361 & USA & $\begin{array}{l}\text { Risk of thyroid cancer increases } \\
\text { with increased TSH } \\
\text { independent of age. }\end{array}$ & No cut-off value \\
\hline Fiore et al. (2009) & $\begin{array}{l}\text { Endocrine Related } \\
\text { Cancer }\end{array}$ & 10,178 & Italy & $\begin{array}{l}\text { Higher TSH in patients with } \\
\text { T3-T4 disease and in those } \\
\text { with lymph node metastases. } \\
\text { Autonomously functioning } \\
\text { thyroid nodules are less likely } \\
\text { to be malignant. }\end{array}$ & $1.6 \mathrm{mlU} / \mathrm{L}$ \\
\hline Gerschpacher et al. (2010) & Thyroid & 87 & Austria & $\begin{array}{l}\text { TSH may play a role in thyroid } \\
\text { cancer progression rather than } \\
\text { oncogenesis. }\end{array}$ & No cut-off value \\
\hline Zafon et al. (2012) & $\begin{array}{l}\text { Journal of Thyroid } \\
\text { Research }\end{array}$ & 386 & Spain & $\begin{array}{l}\text { TSH levels are higher in patients } \\
\text { with DTC.Increment in tumour } \\
\text { size rises in parallel with } \\
\text { incremental rise in TSH. }\end{array}$ & No cut-off value \\
\hline Kim et al. (2013) & Clinical Endocrinology & 1759 & South Korea & $\begin{array}{l}\text { High TSH level within the } \\
\text { normal range is an } \\
\text { independent risk factor for } \\
\text { DTC and can be used as a } \\
\text { diagnostic adjunct. }\end{array}$ & $2.31 \mathrm{mlU} / \mathrm{L}$ \\
\hline Sohn et al. (2014) & Head and Neck & 3791 & South Korea & $\begin{array}{l}\text { Serum TSH may not be useful } \\
\text { for clinical risk assessment of } \\
\text { small thyroid nodules. }\end{array}$ & $2.13 \mathrm{mlU} / \mathrm{L}$ \\
\hline Fighera et al. (2015) & $\begin{array}{l}\text { Endokrynologia } \\
\text { Polska }\end{array}$ & 622 & Brazil & $\begin{array}{l}\text { Risk of carcinoma in nodular } \\
\text { disease rises in parallel with } \\
\text { serum TSH. }\end{array}$ & $1.64 \mathrm{mlU} / \mathrm{L}$ \\
\hline Khan et al. (2016) & $\begin{array}{l}\text { Asian Pacific Journal } \\
\text { of Cancer Preven- } \\
\text { tion }\end{array}$ & 73 & Pakistan & $\begin{array}{l}\text { Higher pre-surgical TSH } \\
\text { correlates with thyroid cancer. }\end{array}$ & No cut-off value \\
\hline Shi et al. (2016) & Endocrine Journal & 1870 & China & $\begin{array}{l}\text { Raised TSH is related to cancer } \\
\text { stage but not likely to be } \\
\text { related to initiation. }\end{array}$ & Meta-analysis \\
\hline
\end{tabular}

*'Cut-off' values from studies that stated a cut-off or divided groups into tertiles and quartiles, in this latter case, the lower value of the highest tertile/ quartile is used.

nodules has confirmed that higher serum TSH levels were significantly associated with thyroid cancer size and with the presence of lymph node metastasis (Zheng et al. 2016). These findings are consistent with serum TSH having a role in the promotion of thyroid tumour growth and aggressiveness. 
Indeed TSH is a known growth factor for thyroid nodules and suppression of serum TSH concentrations by administering exogenous thyroid hormone may inhibit the growth of established nodules and the development of new nodules (Papini et al. 1998). Benign and malignant thyroid tumours express functional TSH receptors on the plasma membrane (Ichikawa et al. 1976) and TSH increases adenylate cyclase activity leading to cAMP production and cell growth through stimulation of these receptors in vitro (Carayon et al. 1980). Importantly, the expression of TSH receptors in DTC has been associated with an improved prognosis (Shi et al. 1993). Differentiated thyroid cancers usually retain responsiveness to TSH, and suppressive doses of levothyroxine can be used to inhibit the progression of metastatic thyroid cancer (Simpson et al. 1988) as well as decrease the rates of recurrence in patients treated with surgery or radioactive iodine (McGriff et al. 2002, Biondi et al. 2005), in keeping with TSH's tropic effect on thyroid tissue promoting neoplasia and carcinogenesis.

\section{TSH and the initiation of thyroid cancer}

It has been demonstrated that even in patients who do not present with thyroid nodules, higher serum TSH concentrations are associated with increased risks of thyroid malignancy. In a large sample drawn from the general population TSH levels were significantly higher in patients with DTC compared with the control group. Among 1548 controls, 606 subjects had thyroid nodules detected on ultrasound. Further subgroup analysis demonstrated that control subjects without detectable thyroid nodules had proportionally higher risks of DTC as TSH concentration rose, suggesting a role for TSH in the generation of thyroid cancer. This study (Kim et al. 2013) did not indicate a relationship between higher serum TSH concentrations and more advanced thyroid cancer in contrast with others (Haymart et al. 2008, Fiore et al. 2009, McLeod et al. 2012, Zheng et al. 2016).

Evidence for a role of TSH in the development of thyroid tumours comes from studies of the ThrbPV/PV mouse, which has a dominant negative mutant thyroid hormone nuclear receptor gene inserted in the TR $\beta$ locus. This mouse model has disrupted pituitary-thyroid axis signalling resulting in raised serum TSH concentrations and the rapid development of metastatic thyroid cancer (Suzuki et al. 2002). Crossing of this model with TSH receptor gene-knockout mice (Tshr/) resulted in impaired thyroid growth and no occurrences of thyroid cancer, consistent with a role for TSH in thyroid tumourigenesis (Lu et al. 2010).

\section{Serum TSH and thyroid autoimmunity}

Several studies have indicated an association between thyroid autoimmunity and thyroid malignancy (Haymart et al. 2008, Boelaert 2009, McLeod et al. 2012). There is an increased incidence of thyroid cancer in patients with Hashimoto's disease. Our previous study (Boelaert et al. 2006) demonstrated that although raised thyroid peroxidase (TPO) levels did not independently predict malignancy, patients with cancer had significantly higher levels of TPO antibody than patients with benign disease. Fiore et al. (2009) demonstrated that TSH was higher in patients independent of whether they had raised TPO antibodies or not, and that there was no difference in rates of thyroid carcinoma between the autoimmune thyroid disease population and antibodynegative patients. Haymart et al. (2008) observed the debate about association of thyroid cancer with both Hashimoto's disease and Graves' disease. They suggest that as Hashimoto's disease often progresses to hypothyroidism resulting in elevated TSH concentrations and because Graves' disease is associated with TSH receptor stimulation, which is associated with thyroid cancer (Mazzaferri 2000), it follows that TSH receptor activation is the link between thyroid cancer and thyroid autoimmune disease. More recently, a study directed at assessment of anti-thyroglobulin antibody (TgAb) measured pre-operative levels in differentiated thyroid cancer patients and concluded that $\operatorname{TgAb}$ was not an independent predictor of DTC prognosis, once adjusted for age and gender (McLeod et al. 2014). They noted that $\mathrm{TgAb}$ may be raised in autoimmunity and in patients exhibiting an immune response to the tumour, and may not be a true representation of thyroid autoimmune disease. Figure 1 summarises the potential effects of TSH as a tumour initiator, cancer promoter or in relation to thyroid autoimmunity.

\section{Aetiology of raised serum TSH concentrations in thyroid cancer}

There is no consensus on why serum TSH is raised in differentiated thyroid cancer nor do we fully understand the cause and effect relationship (Boelaert 2009). Iodine deficiency causes a consequent rise in serum TSH concentrations, and chronic iodine deficiency is a well-established risk factor for the development of goitre and follicular thyroid cancer (Lind et al. 1998, FeldtRasmussen 2001, Nagataki \& Nystrom 2002). However, a causal role for TSH in the initiation of thyroid cancer has

Published by Bioscientifica Ltd. 


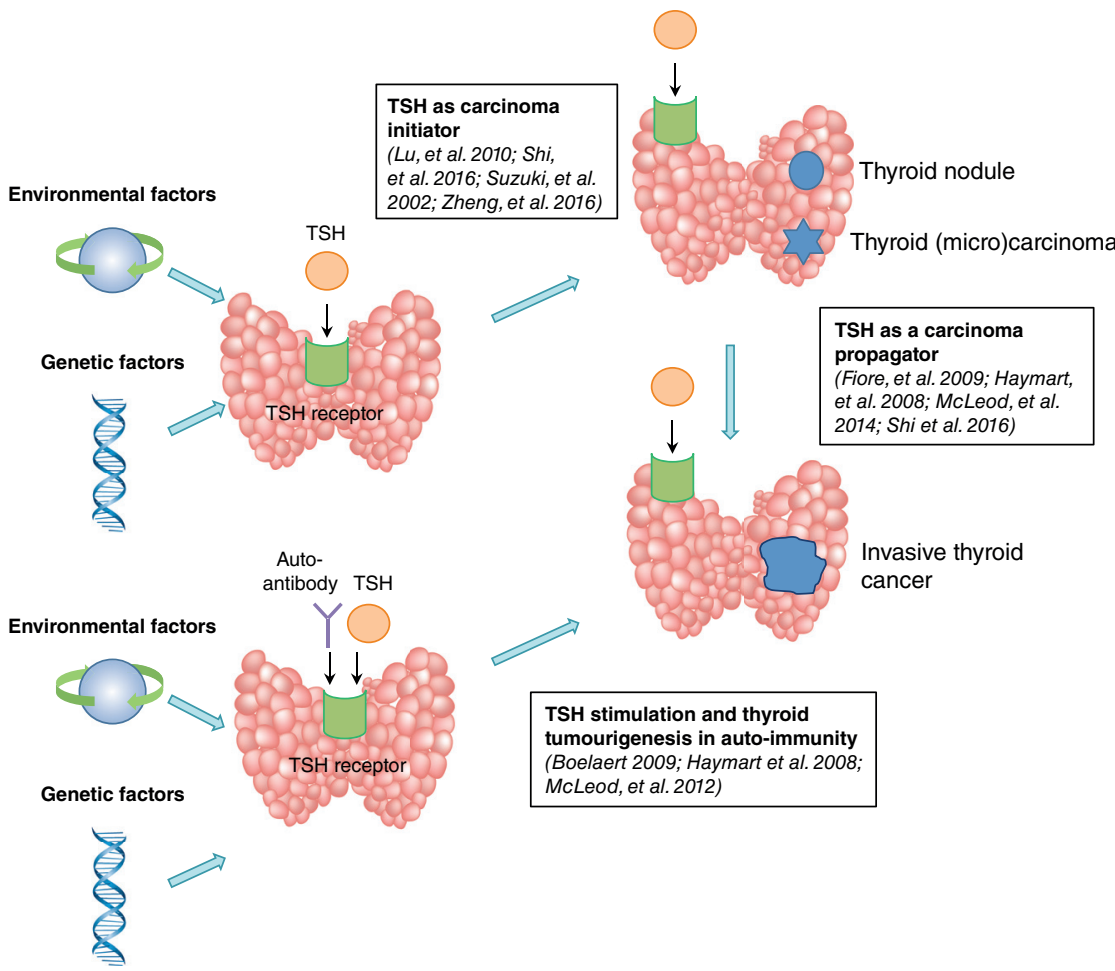

\section{Figure 1}

Illustrating binding of TSH to its receptor in normal thyroid physiology. Potential roles of high serum TSH concentrations in the initiation and progression of thyroid carcinogenesis as well as putative links with thyroid autoimmunity in the context of contributing environmental and genetic factors are indicated. not been exclusively demonstrated, and it remains unclear if serum TSH concentrations are higher as a consequence of the presence of thyroid malignancy.

A further potential explanation is that patients with lower serum TSH concentrations already have or are progressing towards development of autonomously functioning thyroid nodules, which are less likely to be malignant (Mann etal. 1988, Hegedus et al. 2003, Hegedus 2004). Fiore and coworkers demonstrated significant age-dependent development of thyroid autonomy (serum TSH $<0.4 \mathrm{IU} / \mathrm{L}$ ) in patients with benign thyroid disease, but this was less evident in those with papillary thyroid cancer and in patients with multi-nodular goitre. The frequency of thyroid autonomy was higher and the risk of papillary thyroid cancer was lower than in those with solitary nodules, consistent with a protective effect of lower serum TSH concentrations on thyroid cancer development or progression (Boelaert 2009, Fiore et al. 2009).

\section{Serum TSH in different thyroid cancer subtypes}

Serum TSH and papillary microcarcinoma Papillary microcarcinomas, defined as thyroid cancer $<10 \mathrm{~mm}$ in diameter, are increasing dramatically in frequency, and distinguishing those that proliferate and progress aggressively from small indolent tumours is difficult.
The increased incidence is partly due to the finding of incidentalomas on routineimaging and on histopathological examination of thyroid specimens removed for reasons not associated with the suspicion of malignancy (Roti et al. 2008). Current guidelines neither recommend completion thyroidectomy nor the administration of radioiodine routinely for these tumours. A more conservative approach for their management has been recommended, and for low-risk patients, who have isolated and intrathryoidal tumours, without nodal metastases, lobectomy is sufficient (Pacini et al. 2012, Perros et al. 2014, Haugen et al. 2015). In those with evidence of metastases, a positive family history, previous radiation to the head and neck or in subjects older than 45 years, total thyroidectomy and radioiodine ablation may be indicated (Mazzaferri 2007, Perros et al. 2014, Pitoia \& Miyauchi 2015).

Two main difficulties arise from these modern guidelines: (i) a subset of these tumours progresses and metastasises (Roti et al. 2006, Page et al. 2009); (ii) patients, when presented with a cancer diagnosis, often prefer comprehensive therapy, which leaves them with the best prognosis and the lowest risk of recurrence, often despite the potential cost of any associated treatment morbidity. Although current tumour staging systems are unable to guide therapy in papillary microcarcinomas, the potential for use of TSH to assist in assessing prognosis is appealing. 
The association between raised serum TSH measurements and papillary thyroid microcarcinoma has been studied (Table 4), and some have suggested this as a means to estimate thyroid cancer risk in those with thyroid nodule of less than $1 \mathrm{~cm}$ in size (Moon et al. 2012). However, not all studies are consistent. Sohn et al. (2014) demonstrated the association between higher TSH and risk of malignancy in tumours over $1 \mathrm{~cm}$, but not in papillary microcarcinomas. Similarly, an Italian study showed that TSH was not significantly different in thyroid papillary microcarinoma patients compared with their controls consisting of patients with negative histology (Negro et al. 2013, Sohn et al. 2014). A meta-analysis of nine studies encompassing 6523 subjects demonstrated that some smaller studies were biased due to heterogeneous controls, and overall confirmed a significant association between higher serum TSH and papillary microcarcinoma, supporting the hypothesis that TSH is involved in differentiated thyroid tumourigenesis. The authors stated that there is insufficient evidence to show that TSH is directly involved in thyroid carcinoma initiation, but the data support the hypothesis that raised TSH is associated with risk of cancer and progression (Shi et al. 2016). At present, it is unclear how the increased detection of small indolent microcarcinomas influences the utility of using serum TSH in clinical decision algorithms.
Whether TSH is an important factor in disease initiation or progression remains unclear. An argument against its involvement in tumour initiation is the lack of TSH receptor mutations interfering with signal transduction in thyroid carcinomas (Matsuo et al. 1993). Furthermore, thyroid carcinomas can occur in patients with a range of serum $\mathrm{TSH}$, including in those who take exogenous thyroid hormones and have suppressed serum TSH concentrations for treatment of other thyroid diseases (Satta et al. 1993).

On the contrary, a mouse model with a knock-in of oncogenic BRAF generated by Franco and coworkers developed invasive thyroid carcinomas and concomitantly became profoundly hypothyroid as demonstrated by significantly raised TSH levels. After knockout of the $\mathrm{TSH}$ receptor (to genetically replicate ablation of the TSH signalling pathway), there was a significant lag in the period before tumour formation, and the tumours that developed were much less aggressive (Franco et al. 2011). These findings contribute to the idea that TSH per se may not be oncogenic independently, but raised concentrations are likely to contribute significantly to tumour development and progression.

Serum TSH and follicular thyroid cancer Follicular thyroid carcinomas provide a unique diagnostic challenge, in that they cannot be diagnosed by cytological evaluation alone. Although there may be factors indicating neoplastic

Table 4 Table summarising studies investigating TSH and papillary microcarcinoma.

Reference

Haymart et al. (2008)

Journal

Journal of Clinical Endocrinology
and Metabolism

Moon et al. (2012) Head and Neck

Shi et al. (2012)

Negro et al. (2013) Endocrine Practice

Sohn et al. (2014) Head and Neck

Jiao and Zhou (2015) Zhonghua Yi Xue Za Zhi
Nu

483

1870

205

Italy

3791

365

China

China

Country of study
US
South Korea

South Korea

5
Significant findings
Escalating cancer risk with higher TSH level in microcarcinomas. More research warranted TSH measurement in the context of thyroid micronodule can exclude cancer
TSH does not correlate with microcarcinoma presence and therefore TSH can only be linked with progression of carcinoma
No difference in serum TSH between papillary microcarci- noma group compared with controls
Serum TSH may not be useful for clinical risk assessment of small thyroid nodules
TSH is probably associated with oncogenesis in papillary microcarcinoma (PTMC) although it may only be involved in growth of pre-existing PTMC


change in fine needle aspirates, follicular carcinoma is defined as a tumour that invades the capsule, a feature that cannot be identified on cytological evaluation rendering these cancers indistinguishable from thyroid adenomas using cytopathology. The standard treatment of choice is therefore diagnostic hemithyroidectomy, which requires no further surgery in adenomatous lesions, but is usually followed by completion hemithyroidectomy, radioiodine ablation and suppression of TSH in the majority of invasive follicular carcinomas (McHenry \& Phitayakorn 2011, Perros et al. 2014, Pitoia \& Miyauchi 2015).

Raised serum TSH levels have been demonstrated in patients with follicular carcinoma compared with those with benign follicular disease (Kunt et al. 2015). Although the TSH level is unlikely to be the single factor in follicular thyroid cancer development, some have advocated using its measurement in combination with other determinators of risk stratification, even to the point of defining treatment, that is, whether to proceed with hemithyroidectomy or not (Kuru et al. 2009). Despite the potential for the application of TSH measurements in the management of follicular thyroid carcinomas, there is a paucity of studies addressing this specifically (Zheng et al. 2016).

TSH and non-differentiated thyroid cancer Due to the different pathophysiology of medullary thyroid cancer, TSH concentrations are implicated neither in the likelihood of diagnosis nor in the follow-up monitoring of these tumours. Responsiveness of thyroid cancer to TSH depends on TSH receptor expression, and dedifferentiated cancers demonstrate significant reductions in expression of thyroid-specific proteins including TSH receptors, thyroid peroxidase and thyroglobulin (Brabant et al. 1991, Sheils \& Sweeney 1999). Anaplastic thyroid cancers represent extreme forms of dedifferentiated tumours, and these tumours are characteristically very difficult to treat due to the lack of expression of proteins involved in the thyroid machinery. Expression of the sodium iodide symporter is often absent, thereby significantly reducing the functional effectiveness of radioiodine ablation and treatment. Current therapeutic approaches include the redifferentiation of these tumours with various agents to improve treatability (Schmutzler \& Kohrle 2000, Kang et al. 2011, Dong et al. 2013). In view of the inherent lack of expression of normal TSH receptors in anaplastic thyroid cancers, serum TSH concentrations have not been studied in relation to the diagnosis or progression of these tumours. It seems that finding of altered TSH levels in this context would neither aid the choice of available treatment options nor would it affect the very poor prognosis associated with these rare thyroid cancers.

\section{TSH in follow-up of patients with thyroid malignancy}

Until recently, the long-term management of differentiated thyroid cancers included the suppression of serum TSH concentrations with supraphysiological concentrations of levothyroxine for extended periods of time, regardless of the tumour-specific risk stratification. Current guidelines recommend against TSH suppression in low-risk tumours, which have not been treated with radioiodine or those who are stratified in the excellent response categories after dynamic risk stratification (Perros et al. 2014, Haugen et al. 2015, Pitoia \& Miyauchi 2015). For those tumours that have not undergone further risk stratification at 1 year after treatment, current practice is to suppress TSH levels with exogenous thyroid hormone to less than $0.1 \mathrm{U} / \mathrm{L}$ for 5-10 years after treatment. At this point, depending on the clinical response, the TSH suppression can be relaxed (Perros et al. 2014). Some studies have indicated that TSH suppression may inhibit the generation of new thyroid nodules, as well as the growth and tumourigenic potential in existing nodules (Papini et al. 1998), although current guidelines do not recommend of thyroid hormone suppressive therapy in patients with thyroid nodules (Perros et al. 2014, Haugen et al. 2015, Pitoia \& Miyauchi 2015).

\section{TSH suppression in differentiated thyroid cancer follow-up}

Suppressive serum TSH to very low levels reduces the rates of thyroid cancer recurrence and has been shown to improve differentiated thyroid cancer patient outcomes. TSH is a growth factor for thyroid nodules, and it is considered that suppression of TSH can prevent new nodule formation as well as inhibition of current nodules (Papini et al. 1998). In the context of differentiated thyroid carcinoma treatment, after resection of thyroid carcinoma and radioiodine treatment, TSH suppression therapy positively affects cancer outcomes including disease-specific survival (Mazzaferri \& Jhiang 1994), and reduces recurrence (Pujol et al. 1996). Therefore, it is widely recommended that patients have TSH suppression after successful treatment in the early post-operative period (Haugen et al. 2015).

Published by Bioscientifica Ltd. 


\section{Risks associated with TSH suppression}

Despite the widespread use of TSH suppression in patients who have been treated for differentiated thyroid cancer, this treatment approach is not completely without risk. Subclinical hyperthyroidism has been demonstrated to have significant deleterious health consequences. This includes a spectrum of cardiovascular risks, including atrial fibrillation and coronary heart disease morbidity and mortality (Collet et al. 2012). There is also a documented association with dementia, decreased cognitive function (Annerbo \& Lokk 2013) and osteoporosis (Biondi et al. 2015, Polovina et al. 2015).

Outcomes for high-grade thyroid cancers have been improved with TSH suppression, and some advocate the need for more aggressive suppression in higher-stage disease (Jonklaas et al. 2006). In view of the aforementioned risk factors associated with this approach, current guidelines (Perros et al. 2014) now recommend the use of tools including the FRAX score to determine bone health and fracture risk (Kanis et al. 2008) in patients who are on suppressive therapy with levothyroxine for 5 years or longer during thyroid cancer follow-up. Overall, an individualised approach combining assessment of the patient's response to treatment and risk of disease progression with an evaluation of the potential health risks associated with long-term TSH suppression is advised in establishing the required dose and length of course of levothyroxine therapy.

\section{Conclusion}

Patients presenting with a thyroid nodule or thyroid enlargement should have their serum TSH measured as part of the initial assessment. After our paper in 2006 (Boelaert et al. 2006), a significant body of evidence has accumulated confirming the association between higher serum TSH concentrations and likelihood of thyroid cancer diagnosis. A recent meta-analysis demonstrated this relationship in thyroid tumours of all sizes, including papillary microcarcinomas in adult as well as in paediatric thyroid cancers (Zheng et al. 2016). Several studies and meta-analyses have also established a relationship between raised TSH levels and cancer progression, and increased concentrations were associated with advanced disease and lymph node metastasis (Fiore et al. 2009, McLeod et al. 2012, Zheng et al. 2016).

The diagnostic accuracy of serum TSH as a biochemical predictor of malignancy, however, has not yet been established and meta-analyses have failed to provide conclusive data to provide a single useful cut-off value to pass TSH as an independent and validated test (McLeod et al. 2012, Zheng et al. 2016), and measurement of this biochemical marker has not yet been incorporated into clinical decision algorithms. There have been suggestions that its measurement may be useful in combination with other tests including ultrasonography and fine needle aspiration cytology. At a time when thyroid nodules are increasingly being diagnosed, and although the differentiation between benign and malignant lesions remains difficult in a significant proportion of subjects, it is important to consider incorporating TSH levels into the stratification of patients' thyroid cancer risk.

Furthermore, treatment with TSH suppression in the follow-up of patients with thyroid cancer has been re-evaluated. There are significant long-term health risks associated with TSH suppression, and further refinement of the stratification approaches regarding the risk of disease progression or recurrence will help identify those patients in whom the risks of long-term suppressive therapy outweigh the risks. Large prospective studies to evaluate this further will be of utmost importance. Although there is little doubt that serum TSH is raised in differentiated thyroid cancer, the full integration of this finding into clinical pathways relating to the diagnosis and management of patients is yet to be undertaken.

\section{Declaration of interest}

The authors declare that there is no conflict of interest that could be perceived as prejudicing the impartiality of this review.

\section{Funding}

This research did not receive any specific grant from any funding agency in the public, commercial or not-for-profit sector.

Author contribution statement

Both authors were involved with the design, drafting and revision of the article, and have both approved the final version.

\section{References}

American Cancer Society 2015 Cancer Facts and Figures. Atlanta, GA, USA: American Cancer Society. (available at: http://www.cancer.org/acs/ groups/content/@editorial/documents/document/acspc-044552.pdf)

American Cancer Society 2016 Key Statistics for Thyroid Cancer. Atlanta, GA, USA: American Cancer Society. (available at: http://www.cancer org/cancer/thyroidcancer/detailedguide/thyroid-cancer-key-statistics)

Annerbo S \& Lokk J 2013 A clinical review of the association of thyroid stimulating hormone and cognitive impairment. ISRN Endocrinology 2013856017.

Bernet V, Hupart KH, Parangi S \& Woeber KA 2014 AACE/ACE disease state commentary: molecular diagnostic testing of thyroid nodules with indeterminate cytopathology. Endocrine Practice 20 360-363. (doi:10.4158/EP14066.PS) 
Biondi B, Bartalena L, Cooper DS, Hegedus L, Laurberg P \& Kahaly GJ 2015 The 2015 European Thyroid Association Guidelines on diagnosis and treatment of endogenous subclinical hyperthyroidism. European Thyroid Journal 4 149-163. (doi:10.1159/000438750)

Biondi B, Filetti S \& Schlumberger M 2005 Thyroid-hormone therapy and thyroid cancer: a reassessment. Nature Clinical Practice Endocrinology and Metabolism 1 32-40. (doi:10.1038/ncpendmet0020)

Boelaert K 2009 The association between serum TSH concentration and thyroid cancer. Endocrine-Related Cancer 16 1065-1072. (doi:10.1677/ ERC-09-0150)

Boelaert K, Horacek J, Holder RL, Watkinson JC, Sheppard MC \& Franklyn JA 2006 Serum thyrotropin concentration as a novel predictor of malignancy in thyroid nodules investigated by fineneedle aspiration. Journal of Clinical Endocrinology and Metabolism 91 4295-4301. (doi:10.1210/jc.2006-0527)

Bongiovanni M, Spitale A, Faquin WC, Mazzucchelli L \& Baloch ZW 2012 The Bethesda System for Reporting Thyroid Cytopathology: a meta-analysis. Acta Cytologica 56 333-339. (doi:10.1159/000339959)

Brabant G, Maenhaut C, Kohrle J, Scheumann G, Dralle H, Hoang-Vu C, Hesch RD, von zur Muhlen A, Vassart G \& Dumont JE 1991 Human thyrotropin receptor gene: expression in thyroid tumors and correlation to markers of thyroid differentiation and dedifferentiation. Molecular and Cellular Endocrinology 82 R7-R12. (doi:10.1016/0303-7207(91)90018-N)

Brito JP, Hay ID \& Morris JC 2014 Low risk papillary thyroid cancer. BMJ 348 g3045. (doi:10.1136/bmj.g3045)

Burns WR \& Zeiger MA 2010 Differentiated thyroid cancer. Seminars in Oncology 37 557-566. (doi:10.1053/j.seminoncol.2010.10.008)

Cabanillas ME, McFadden DG \& Durante C $2016 a$ Thyroid cancer Lancet [in press]. (doi:10.1016/S0140-6736(16)30172-6)

Cabanillas ME, Zafereo M, Gunn GB \& Ferrarotto R 2016b Anaplastic thyroid carcinoma: treatment in the age of molecular targeted therapy. Journal of Oncology Practice 12 511-518. (doi:10.1200/ JOP.2016.012013)

Carayon P, Thomas-Morvan C, Castanas E \& Tubiana M 1980 Human thyroid cancer: membrane thyrotropin binding and adenylate cyclase activity. Journal of Clinical Endocrinology and Metabolism $\mathbf{5 1}$ 915-920. (doi:10.1210/jcem-51-4-915)

Cesur M, Corapcioglu D, Bulut S, Gursoy A, Yilmaz AE, Erdogan N \& Kamel N 2006 Comparison of palpation-guided fine-needle aspiration biopsy to ultrasound-guided fine-needle aspiration biopsy in the evaluation of thyroid nodules. Thyroid 16 555-561. (doi:10.1089/thy.2006.16.555)

Collet TH, Gussekloo J, Bauer DC, den Elzen WP, Cappola AR, Balmer P, Iervasi G, Asvold BO, Sgarbi JA, Volzke H, et al. 2012 Subclinical hyperthyroidism and the risk of coronary heart disease and mortality. Archives of Internal Medicine 172 799-809. (doi:10.1001/ archinternmed.2012.1114)

Cramer JD, Fu P, Harth KC, Margevicius S \& Wilhelm SM 2010 Analysis of the rising incidence of thyroid cancer using the surveillance, epidemiology and end results national cancer data registry. Surgery 148 1147-1152, discussion 1152-1143. (doi:10.1016/j. surg.2010.10.016)

Dean DS \& Gharib H 2008 Epidemiology of thyroid nodules. Best Practice and Research Clinical Endocrinology and Metabolism 22 901-911. (doi:10.1016/j.beem.2008.09.019)

Dong JJ, Zhou Y, Liu YT, Zhang ZW, Zhou XJ, Wang HJ \& Liao L 2013 In vitro evaluation of the therapeutic potential of nevirapine in treatment of human thyroid anaplastic carcinoma. Molecular and Cellular Endocrinology 370 113-118. (doi:10.1016/j.mce.2013.02.001)

Durante C, Costante G, Lucisano G, Bruno R, Meringolo D, Paciaroni A, Puxeddu E, Torlontano M, Tumino S, Attard M, et al. 2015 The natural history of benign thyroid nodules. JAMA 313 926-935. (doi:10.1001/jama.2015.0956)

Feldt-Rasmussen U 2001 Iodine and cancer. Thyroid 11 483-486. (doi:10.1089/105072501300176435)
Fighera TM, Perez CL, Faris N, Scarabotto PC, da Silva TT, Cavalcanti TC, Mesa Junior CO, Miasaki F, da Paz Filho GJ \& de Carvalho GA 2015 TSH levels are associated with increased risk of thyroid carcinoma in patients with nodular disease. Endokrynologia Polska 66 480-485. (doi:10.5603/EP.a2015.0059)

Fiore E, Rago T, Provenzale MA, Scutari M, Ugolini C, Basolo F, Di Coscio G, Berti P, Grasso L, Elisei R, et al. 2009 Lower levels of TSH are associated with a lower risk of papillary thyroid cancer in patients with thyroid nodular disease: thyroid autonomy may play a protective role. Endocrine-Related Cancer 16 1251-1260. (doi:10.1677/ ERC-09-0036)

Franco AT, Malaguarnera R, Refetoff S, Liao XH, Lundsmith E, Kimura S, Pritchard C, Marais R, Davies TF, Weinstein LS, et al. 2011

Thyrotrophin receptor signaling dependence of Braf-induced thyroid tumor initiation in mice. PNAS 108 1615-1620. (doi:10.1073/ pnas.1015557108)

Frates MC, Benson CB, Charboneau JW, Cibas ES, Clark OH, Coleman BG, Cronan JJ, Doubilet PM, Evans DB, Goellner JR, et al. 2005 Management of thyroid nodules detected at US: Society of Radiologists in Ultrasound consensus conference statement. Radiology 237 794-800. (doi:10.1148/radiol.2373050220)

Gerschpacher M, Gobl C, Anderwald C, Gessl A \& Krebs M 2010 Thyrotropin serum concentrations in patients with papillary thyroid microcancers. Thyroid 20 389-392. (doi:10.1089/thy.2009.0139)

Hambly NM, Gonen M, Gerst SR, Li D, Jia X, Mironov S, Sarasohn D, Fleming SE \& Hann LE 2011 Implementation of evidence-based guidelines for thyroid nodule biopsy: a model for establishment of practice standards. American Journal of Roentgenology 196 655-660. (doi:10.2214/AJR.10.4577)

Haugen BRM, Alexander EK, Bible KC, Doherty G, Mandel SJ, Nikiforov YE, Pacini F, Randolph G, Sawka A, Schlumberger M, et al. 2015 American Thyroid Association Management Guidelines for adult patients with thyroid nodules and differentiated thyroid cancer. Thyroid 26 1-133. (doi:10.1089/thy.2015.0020)

Haymart MR, Glinberg SL, Liu J, Sippel RS, Jaume JC \& Chen H 2009 Higher serum TSH in thyroid cancer patients occurs independent of age and correlates with extrathyroidal extension. Clinical Endocrinology 71 434-439. (doi:10.1111/ j.1365-2265.2008.03489.x)

Haymart MR, Repplinger DJ, Leverson GE, Elson DF, Sippel RS, Jaume JC \& Chen H 2008 Higher serum thyroid stimulating hormone level in thyroid nodule patients is associated with greater risks of differentiated thyroid cancer and advanced tumor stage. Journal of Clinical Endocrinology and Metabolism 93 809-814. (doi:10.1210/ jc.2007-2215)

He LZ, Zeng TS, Pu L, Pan SX, Xia WF \& Chen LL 2016 Thyroid hormones, autoantibodies, ultrasonography, and clinical parameters for predicting thyroid cancer. International Journal of Endocrinology 2016 8215834. (doi:10.1155/2016/8215834)

Hegedus L 2004 Clinical practice. The thyroid nodule. New England Journal of Medicine 351 1764-1771. (doi:10.1056/NEJMcp031436)

Hegedus L, Bonnema SJ \& Bennedbaek FN 2003 Management of simple nodular goiter: current status and future perspectives. Endocrine Reviews 24 102-132. (doi:10.1210/er.2002-0016)

Ichikawa Y, Saito E, Abe Y, Homma M \& Muraki T 1976 Presence of TSH receptor in thyroid neoplasms. Journal of Clinical Endocrinology and Metabolism 42 395-398. (doi:10.1210/jcem-42-2-395)

Jiao J \& Zhou Y 2015 Relationship between serum thyroxin-stimulating hormone and papillary thyroid micrcarcinoma in nodular thyroid disease. Zhonghua Yi Xue Za Zhi 95 908-911.

Jonklaas J, Nsouli-Maktabi H \& Soldin SJ 2008 Endogenous thyrotropin and triiodothyronine concentrations in individuals with thyroid cancer. Thyroid 18 943-952. (doi:10.1089/thy.2008.0061)

Jonklaas J, Sarlis NJ, Litofsky D, Ain KB, Bigos ST, Brierley JD, Cooper DS, Haugen BR, Ladenson PW, Magner J, et al. 2006 Outcomes of patients with differentiated thyroid carcinoma 
following initial therapy. Thyroid 16 1229-1242. (doi:10.1089/ thy.2006.16.1229)

Kang HJ, Youn YK, Hong MK \& Kim LS 2011 Antiproliferation and redifferentiation in thyroid cancer cell lines by polyphenol phytochemicals. Journal of Korean Medical Science 26 893-899. (doi:10.3346/jkms.2011.26.7.893)

Kanis JA, Johnell O, Oden A, Johansson H \& McCloskey E 2008 FRAX ${ }^{\mathrm{TM}}$ and the assessment of fracture probability in men and women from the UK. Osteoporosis International 19 385-397. (doi:10.1007/s00198007-0543-5)

Khan MA, Khan KH, Shah SA, Mir KA, Khattak M \& Shahzad MF 2016 Risk factors associated with thyroid carcinoma in North Pakistan. Asian Pacific Journal of Cancer Prevention 17 377-380. (doi:10.7314/ APJCP.2016.17.1.377)

Kim HK, Yoon JH, Kim SJ, Cho JS, Kweon SS \& Kang HC 2013 Higher TSH level is a risk factor for differentiated thyroid cancer. Clinical Endocrinology 78 472-477. (doi:10.1111/cen.12027)

Kitahara CM \& Sosa JA 2016 The changing incidence of thyroid cancer Nature Reviews Endocrinology [in press]. (doi:10.1038/nrendo.2016.110)

Kunt M, Cirit E, Eray IC, Yalay O, Parsak CK \& Sakmann G 2015 Parameters predicting follicular carcinoma in thyroid nodules with indeterminate cytology. Annali Italiani di Chirurgia 86 301-306.

Kuru B, Gulcelik NE, Gulcelik MA \& Dincer H 2009 Predictive index for carcinoma of thyroid nodules and its integration with fine-needle aspiration cytology. Head and Neck 31 856-866. (doi:10.1002/ hed.21049)

Lee YH, Kim DW, In HS, Park JS, Kim SH, Eom JW, Kim B, Lee EJ \& Rho MH 2011 Differentiation between benign and malignant solid thyroid nodules using an US classification system. Korean Journal of Radiology 12 559-567. (doi:10.3348/kjr.2011.12.5.559)

Lind P, Langsteger W, Molnar M, Gallowitsch HJ, Mikosch P \& Gomez I 1998 Epidemiology of thyroid diseases in iodine sufficiency. Thyroid 8 1179-1183. (doi:10.1089/thy.1998.8.1179)

Lu C, Zhao L, Ying H, Willingham MC \& Cheng SY 2010 Growth activation alone is not sufficient to cause metastatic thyroid cancer in a mouse model of follicular thyroid carcinoma. Endocrinology 151 1929-1939. (doi:10.1210/en.2009-1017)

Magner JA 1989 Thyroid-stimulating hormone: structure and function. In Control of the Thyroid Gland: Regulation of Its Normal Function and Growth, pp 27-103. Eds R Ekholm, LD Kohn \& SH Wollman. Boston, MA, USA: Springer US.

Mann K, Saller B, Mehl U, Hormann R \& Moser E 1988 Highly sensitive determination of TSH in the follow-up of TSH-suppressive therapy of patients with differentiated thyroid cancer. Nuklearmedizin 27 24-28.

Matsuo K, Friedman E, Gejman PV \& Fagin JA 1993 The thyrotropin receptor (TSH-R) is not an oncogene for thyroid tumors: structural studies of the TSH-R and the alpha-subunit of Gs in human thyroid neoplasms. Journal of Clinical Endocrinology and Metabolism 76 1446-1451. (doi:10.1210/jcem.76.6.8501149)

Mazzaferri EL 1992 Thyroid cancer in thyroid nodules: finding a needle in the haystack. American Journal of Medicine 93 359-362. (doi:10.1016/0002-9343(92)90163-6)

Mazzaferri EL 2000 Thyroid cancer and Graves' disease: the controversy ten years later. Endocrine Practice 6 221-225. (doi:10.4158/EP.6.2.221)

Mazzaferri EL 2007 Management of low-risk differentiated thyroid cancer. Endocrine Practice 13 498-512. (doi:10.4158/EP.13.5.498)

Mazzaferri EL \& Jhiang SM 1994 Long-term impact of initial surgical and medical therapy on papillary and follicular thyroid cancer. American Journal of Medicine 97 418-428. (doi:10.1016/00029343(94)90321-2)

McGriff NJ, Csako G, Gourgiotis L, Lori CG, Pucino F \& Sarlis NJ 2002 Effects of thyroid hormone suppression therapy on adverse clinical outcomes in thyroid cancer. Annals of Medicine 34 554-564. (doi:10.1080/078538902321117760)
McHenry CR \& Phitayakorn R 2011 Follicular adenoma and carcinoma of the thyroid gland. Oncologist 16 585-593. (doi:10.1634/ theoncologist.2010-0405)

McLeod DS, Cooper DS, Ladenson PW, Ain KB, Brierley JD, Fein HG, Haugen BR, Jonklaas J, Magner J, Ross DS, et al. 2014 Prognosis of differentiated thyroid cancer in relation to serum thyrotropin and thyroglobulin antibody status at time of diagnosis. Thyroid $\mathbf{2 4}$ 35-42. (doi:10.1089/thy.2013.0062)

McLeod DS, Watters KF, Carpenter AD, Ladenson PW, Cooper DS \& Ding EL 2012 Thyrotropin and thyroid cancer diagnosis: a systematic review and dose-response meta-analysis. Journal of Clinical Endocrinology and Metabolism 97 2682-2692. (doi:10.1210/ jc.2012-1083)

Monson JP 2000 The epidemiology of endocrine tumours. Endocrine-Related Cancer 7 29-36. (doi:10.1677/erc.0.0070029)

Moon SS, Lee YS, Lee IK \& Kim JG 2012 Serum thyrotropin as a risk factor for thyroid malignancy in euthyroid subjects with thyroid micronodule. Head and Neck 34 949-952. (doi:10.1002/hed.21828)

Nagataki S \& Nystrom E 2002 Epidemiology and primary prevention of thyroid cancer. Thyroid 12 889-896. (doi:10.1089/10507250276 1016511)

Negro R, Valcavi R, Riganti F, Toulis KA, Colosimo E, Bongiovanni M, Grassi P, Giovanella L, Gardini G \& Piana S 2013 Thyrotropin values in patients with micropapillary thyroid cancer versus benign nodular disease. Endocrine Practice 19 651-655. (doi:10.4158/EP12385.OR)

Pacini F, Castagna MG, Brilli L \& Pentheroudakis G 2012 Thyroid cancer: ESMO Clinical Practice Guidelines for diagnosis, treatment and follow-up. Annals of Oncology 23 (Supplement 7) vii110-vii119. (doi:10.1093/annonc/mds230)

Page C, Biet A, Boute P, Cuvelier P \& Strunski V 2009 'Aggressive papillary' thyroid microcarcinoma. European Archives of Oto-RhinoLaryngology 266 1959-1963. (doi:10.1007/s00405-009-0952-5)

Papini E, Petrucci L, Guglielmi R, Panunzi C, Rinaldi R, Bacci V, Crescenzi A, Nardi F, Fabbrini R \& Pacella CM 1998 Long-term changes in nodular goiter: a 5-year prospective randomized trial of levothyroxine suppressive therapy for benign cold thyroid nodules. Journal of Clinical Endocrinology and Metabolism 83 780-783. (doi:10.1210/jcem.83.3.4615)

Perros P, Boelaert K, Colley S, Evans C, Evans RM, Gerrard Ba G, Gilbert J, Harrison B, Johnson SJ, Giles TE, et al. 2014 Guidelines for the management of thyroid cancer. Clinical Endocrinology 81 1-122. (doi:10.1111/cen.12515)

Pitoia F \& Miyauchi A 2015 American Thyroid Association Guidelines for thyroid nodules and differentiated thyroid cancer and their implementation in various care settings. Thyroid 26 319-321. (doi:10.1089/thy.2015.0530)

Polovina S, Micic D, Miljic D, Milic N, Micic D \& Popovic V 2015 The Fracture Risk Assessment Tool (FRAX score) in subclinical hyperthyroidism. Vojnosanitetski Pregled 72 510-516. (doi:10.2298/ VSP1506510P)

Polyzos SA, Kita M, Efstathiadou Z, Poulakos P, Slavakis A, Sofianou D, Flaris N, Leontsini M, Kourtis A \& Avramidis A 2008 Serum thyrotropin concentration as a biochemical predictor of thyroid malignancy in patients presenting with thyroid nodules. Journal of Cancer Research and Clinical Oncology 134 953-960. (doi:10.1007/ s00432-008-0373-7)

Popoveniuc G \& Jonklaas J 2012 Thyroid nodules. Medical Clinics of North America 96 329-349. (doi:10.1016/j.mcna.2012.02.002)

Pujol P, Daures JP, Nsakala N, Baldet L, Bringer J \& Jaffiol C 1996 Degree of thyrotropin suppression as a prognostic determinant in differentiated thyroid cancer. Journal of Clinical Endocrinology and Metabolism 81 4318-4323. (doi:10.1210/jc.81.12.4318)

Rago T, Di Coscio G, Basolo F, Scutari M, Elisei R, Berti P, Miccoli P, Romani R, Faviana P, Pinchera A, et al. 2007 Combined clinical, thyroid ultrasound and cytological features help to predict thyroid malignancy in follicular and Hürthle cell thyroid lesions:

Published by Bioscientifica Ltd. 
results from a series of 505 consecutive patients. Clinical Endocrinology 66 13-20.

Roti E, degli Uberti EC, Bondanelli M \& Braverman LE 2008 Thyroid papillary microcarcinoma: a descriptive and meta-analysis study. European Journal of Endocrinology 159 659-673. (doi:10.1530/EJE07-0896)

Roti E, Rossi R, Trasforini G, Bertelli F, Ambrosio MR, Busutti L, Pearce EN, Braverman LE \& Degli Uberti EC 2006 Clinical and histological characteristics of papillary thyroid microcarcinoma: results of a retrospective study in 243 patients. Journal of Clinical Endocrinology and Metabolism 91 2171-2178. (doi:10.1210/jc.2005-2372)

Sangalli G, Serio G, Zampatti C, Bellotti M \& Lomuscio G 2006 Fine needle aspiration cytology of the thyroid: a comparison of 5469 cytological and final histological diagnoses. Cytopathology $\mathbf{1 7}$ 245-250. (doi:10.1111/j.1365-2303.2006.00335.x)

Sarapura VD, Gordon DF \& Samuels MH 2011 Chapter 6 - Thyroidstimulating Hormone A2 - Melmed, Shlomo. In The Pituitary, Third Edition, pp 167-203. San Diego, CA, USA: Academic Press.

Satta MA, De Rosa G, Testa A, Maussier ML, Valenza V, Rabitti C, Saletnich I, D’Ugo D \& Picciocchi A 1993 Thyroid cancer in suppressed contralateral lobe of patients with hot thyroid nodule. European Journal of Cancer 29a 1190-1192. (doi:10.1016/S0959-8049(05)80313-2)

Schmid D, Ricci C, Behrens G \& Leitzmann MF 2015 Adiposity and risk of thyroid cancer: a systematic review and meta-analysis. Obesity Reviews 16 1042-1054. (doi:10.1111/obr.12321)

Schmutzler C \& Kohrle J 2000 Retinoic acid redifferentiation therapy for thyroid cancer. Thyroid 10 393-406. (doi:10.1089/thy.2000.10.393)

Sheils OM \& Sweeney EC 1999 TSH receptor status of thyroid neoplasms - TaqMan RT-PCR analysis of archival material. Journal of Pathology 188 87-92. (doi:10.1002/(SICI)1096-9896(199905)188:1<87::AIDPATH322>3.0.CO;2-5)

Shi L, Li Y, Guan H, Li C, Shi L, Shan Z \& Teng W 2012 Usefulness of serum thyrotropin for risk prediction of differentiated thyroid cancers does not apply to microcarcinomas: results of 1870 Chinese patients with thyroid nodules. Endocrine Journal 59 973-980. (doi:10.1507/endocri.EJ12-0154)

Shi RL, Liao T, Qu N, Liang F, Chen JY \& Ji QH 2016 The usefulness of preoperative thyroid-stimulating hormone for predicting differentiated thyroid microcarcinoma. Otolaryngology Head and Neck Surgery 154 256-262. (doi:10.1177/0194599815618388)

Shi Y, Zou M \& Farid NR 1993 Expression of thyrotrophin receptor gene in thyroid carcinoma is associated with a good prognosis.
Clinical Endocrinology 39 269-274. (doi:10.1111/j.1365-2265.1993. tb02365.x)

Simpson WJ, Panzarella T, Carruthers JS, Gospodarowicz MK \& Sutcliffe SB 1988 Papillary and follicular thyroid cancer: impact of treatment in 1578 patients. International Journal of Radiation Oncology, Biology, Physics 14 1063-1075. (doi:10.1016/0360-3016(88)90381-1)

Sipos JA \& Mazzaferri EL 2010 Thyroid cancer epidemiology and prognostic variables. Clinical Oncology 22 395-404. (doi:10.1016/j. clon.2010.05.004)

Sohn SY, Kim HJ, Jang HW, Kim SW \& Chung JH 2014 Lack of association between high serum thyroid-stimulating hormone level and risk of papillary thyroid microcarcinomas. Head and Neck $\mathbf{3 6}$ 43-46. (doi:10.1002/hed.23252)

Suzuki H, Willingham MC \& Cheng SY 2002 Mice with a mutation in the thyroid hormone receptor beta gene spontaneously develop thyroid carcinoma: a mouse model of thyroid carcinogenesis. Thyroid 12 963-969. (doi:10.1089/105072502320908295)

Szkudlinski MW, Fremont V, Ronin C \& Weintraub BD 2002 Thyroid-stimulating hormone and thyroid-stimulating hormone receptor structure-function relationships. Physiological Reviews $\mathbf{8 2}$ 473-502. (doi:10.1152/physrev.00031.2001)

The Royal College of Pathologists 2009 Guidance on the Reporting of Thyroid Cytology Specimens. London, UK: The Royal College of Pathologists. (available at: https://www.rcpath.org/resourceLibrary/ g089-guidancereportingthyroidcytology-jan16.html)

Vigneri R, Malandrino P \& Vigneri P 2015 The changing epidemiology of thyroid cancer: why is incidence increasing? Current Opinion in Oncology 27 1-7. (doi:10.1097/CCO.0000000000000148)

Wartofsky L 2010 Increasing world incidence of thyroid cancer: increased detection or higher radiation exposure? Hormones 9 103-108. (doi:10.14310/horm.2002.1260)

Xing M, Haugen BR \& Schlumberger M 2013 Progress in molecularbased management of differentiated thyroid cancer. Lancet $\mathbf{3 8 1}$ 1058-1069. (doi:10.1016/S0140-6736(13)60109-9)

Zafon C, Obiols G, Baena JA, Castellvi J, Dalama B \& Mesa J 2012 Preoperative thyrotropin serum concentrations gradually increase from benign thyroid nodules to papillary thyroid microcarcinomas then to papillary thyroid cancers of larger size. Journal of Thyroid Research 2012 530721. (doi:10.1155/2012/530721)

Zheng J, Li C, Lu W, Wang C \& Ai Z 2016 Quantitative assessment of preoperative serum thyrotropin level and thyroid cancer. Oncotarget 7 34918-34929.

Received in final form 13 September 2016

Accepted 15 September 2016

Accepted Preprint published online 15 September 2016
(C) 2016 Society for Endocrinology Printed in Great Britain
Published by Bioscientifica Ltd 